\title{
Suitability of Unmanned Aerial Vehicles for Cadastral Surveys*
}

\author{
${ }^{1}$ S. Mantey and ${ }^{1}$ N. D. Tagoe \\ ${ }^{1}$ University of Mines and Technology, Box 237, Tarkwa, Ghana
}

Mantey, S. and Tagoe, N. D., (2019), "Suitability of Unmanned Aerial Vehicles for Cadastral Surveys", Ghana Mining Journal, Vol. 19, No. 1, pp. 1 - 8.

\begin{abstract}
Cadastral surveys in Ghana often employ well known surveying equipment such as Total Station and GNSS receivers or a combination of both. These survey techniques are well-established and widely accepted. However, there are limitations in certain areas. In situations where difficult terrain and inaccessible areas and dense vegetation are encountered or when surveyor's life may be at risk, Unmanned Aerial Vehicles (UAVs) could be used to overcome the limitations of these wellestablished survey instruments. This research used high resolution images from UAV (DJI Phantom 4) to survey plots within the University of Mines and Technology land area. Coordinates of the boundary points were extracted using Agisoft Photoscan. GNSS receivers were also used to survey the land and the same boundary point coordinates obtained and compared. This enabled the establishment of accurate ground control points for georeferencing. The coordinates obtained from both UAV and GNSS Surveys were used to prepare cadastral plans and compared. The difference in Northings and Eastings from UAV and GNSS surveys were $+0.380 \mathrm{~cm}$ and $+0.351 \mathrm{~cm}$ respectively. These differences are well within

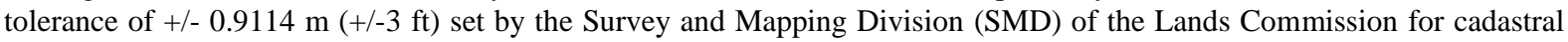
plans production. This research therefore concludes that high resolution images from UAVs are suitable for cadastral surveying.
\end{abstract}

Keywords: Unmanned Aerial Vehicles, Drones, Global Navigation Satellite Systems, Cadastral Surveys

\section{Introduction}

Defining land ownership requires the use of cadastral maps. A cadastral map consists of cadastral units each of which represents a single registered plot of land (Williamson, 1997). Cadastral maps are often produced using land survey techniques which often employ well known surveying equipment such as Total Stations and Global Navigation Satellite Systems (GNSS) or combination of both. These techniques are well established, however, they are sometimes unfavourable in some conditions. When surveying a very large area, the cost involved could be prohibitive and time consuming. In crowded urban settings where subdivision surveys are normally conducted, there are challenges because these tools require point-to-point visibility and enough satellite reception. Sometimes, the safety of personnel carrying out the survey is also jeopardised. Some challenges associated with land boundaries such as litigations are sometimes easily and clearly pointed out on high resolution images which are captured using Unmanned Aerial Vehicle (UAV). UAV also called a drone is an aircraft system with no human being on board (Saripalli et al., 2003; Valavanis, 2008; Anon., 2017). UAV Surveys can solve some challenges associated with land surveying techniques (Eisenbeiss, 2011; Everaerts, 2008) and also create alternatives for cadastral surveying (Darwin et al., 2013). The study area is located between longitudes $2^{\circ} 0^{\prime} 45.76^{\prime \prime} \mathrm{W}$ and $2^{\circ} 0^{\prime} 42.51^{\prime \prime} \mathrm{W}$ and latitudes $5^{\circ} 17^{\prime} 49.48^{\prime \prime} \mathrm{N}$ and $5^{\circ} 17^{\prime} 47.52^{\prime \prime} \mathrm{N}$ within Tarkwa Nsuaem Municipality which was created from the former Wassa West District under
Legislative Instrument (LI) 1886 in 2007. It shares boundary with Prestea Huni-Valley to the North, the South by Ahanta West, the West by Nzema East and the East by Mpohor Wassa East. The Municipality has a total land area of 2354 sqkm, and has Tarkwa as its capital (Anon., 2012).

\subsection{Cadastral Surveys}

Cadastral surveys are carried out to produce cadastral maps. Cadastral map is the spatial representation of cadastre records, which is defined as the records showing the extent, value and ownership (or other basis for use or occupancy) of land (Williamson, 1997). Cadastral map is also the basis for planning economic and social development (Kavannagh and Glenn Bird, 2000). Cadastral map is one of the most important elements of the society, therefore the accurate cadastral information is needed to foster development (Kavannagh and Glenn Bird, 2000).

\subsection{Well-Established Surveying Techniques}

Total Station and GNSS receivers are wellestablished equipment mostly used in land surveying techniques. Total Station and GNSS receivers are widely accepted and are still in use for data acquisition for cadastral mapping purposes. When two control points are known in the area, the collection of survey data can be carried out using Total Station. Whatever the method, the provision of control points, includes the measurement of two entities (Distance and Angle) (Kavannagh and Glenn Bird, 2000). The measurement results can be 
recorded into the internal memory for further processing. GNSS receivers on the other hand, has been used primarily as a means of densifying geodetic control networks, or establishing such networks in areas where they had not previously existed. While GNSS receivers appears to be an attractive alternative for surveying at the parcel level, there are few studies that have tested the cost-efficiency of a GNSS methodology compared with other approaches (Barry and Coakley, 2013). Mostly using GNSS receivers and Total Stations for cadastral surveys is often labour intensive and sometimes exposes surveyors to hazardous environments. Alternative methods of cadastral survey such as the application of UAVs are suggested to minimise the exposure of surveyors to hazardous environments while maintaining accuracy and standards.

\subsection{UAV Surveys}

UAV Surveys require a proper mission planning for a successful flight. Planning the mission is determined by a number of factors, i.e. the desired ground resolution, the focal length and resolution of the camera and the flying height (Lee, et al., 2015; Manyoky et al., 2011). The simple calculations that integrate these factors to create flight plans with corresponding spatial resolution of digital maps is commonly expressed as the Ground Sampling Distance (GSD). GSD is the dimension of a square on the ground covered by one pixel (p) in the image and is a function of the resolution of the camera sensor, the focal length (f) of the camera and the flying height $(\mathrm{H}=$ the distance between camera and ground). From simple geometry the following ratio holds: GSD/p=H/f or $\mathrm{H}=\mathrm{GSD}(\mathrm{f} / \mathrm{p})$. The pixel size (p) of the camera sensor is usually computed from the technical specifications of the camera. Commonly, the dimensions of the sensor are specified both in linear units (e.g. $17.3 \times 13.0 \mathrm{~mm})$ as well as in number of pixels (e.g. $4000 \times 3000$ pixels). Pixel size is simply determined by dividing the linear units by the number of pixels. In UAV surveys, it is essential to capture imagery with sufficient stereo overlap to generate 3D models (Manyoky et al., 2011; Merz and Chapman, 2011). Once a flying height has been determined it is necessary to compute the distance between each exposure position, the spacing between flight lines and the overlap (Witayangkurn et al., 2011).

\subsection{Major Components of UAV}

A basic flight control system for these UAVs contains an Inertial Measurement Unit (IMU) linked to a processor that manages power distribution to the motors to stabilise flight. Most flight control systems also include; a magnetometer, a barometer as well as a Global Navigation Satellite System (GNSS) receiver to support three dimensional navigations of the UAV. A typical UAV consists of airborne components (vehicle, camera, battery, gimbal, etc.) and the ground-based components (base station and a radio control (RC) transmitter to remotely control the UAV (Ferruz et al., 2011; Manyoky et al., 2011). Although it is possible for the flight controller to control the UAV autonomously, it is generally a good idea to have a RC transmitter so that you can control the UAV if something goes wrong or just use the RC transmitter to fly manually (Ferruz et al., 2011; Lippiello and Siciliano 2012). All three of the basic components; the vehicle, base station and RC transmitter, are equipped with appropriate telecommunication devices which facilitate the transfer of data and instructions from and to the UAV. Although most UAVs have the inherent capability to execute automated flights from takeoff to landing without any manual operator input or any connection to the ground components, few are configured to actually function without prior establishment of a live link to either RC transmitter or base station. The RC transmitter constraint is implemented mainly as a safety precaution to ensure that manual control of the UAV can be resumed if needed at any given point during a flight (Ferruz et al., 2011; Manyoky et al., 2011).

\section{Resources and Methods Used}

\subsection{Resources}

The UAV used for this study is the DJI Phantom 4 Drone (Fig. 1) with the following specifications indicated in Table 1. In addition to the DJI Phantom 4 Drone, printed targets or Ground Control Points (GCP) were also used (Fig. 2). The GCPs or printed targets were carefully designed so that the most exact centre of the marker could be determined with a very high degree of accuracy. Furthermore, South S86 GNSS receiver (Fig. 3) was also used to determine coordinates on GCPs to provide photo control. The GNSS receiver was also used to survey all the boundary of the land parcel. The GNSS unit has static horizontal and vertical accuracies of $3 \mathrm{~mm}+0.5 \mathrm{ppm}$ Root Mean Square (RMS) and $5 \mathrm{~mm}+0.5 \mathrm{ppm}$ RMS respectively. The centering position of the GNSS receiver was given an error margin of $\pm 2 \mathrm{~cm}$ due to the fact that error of the exact centre is not the same as that of the UAV. 


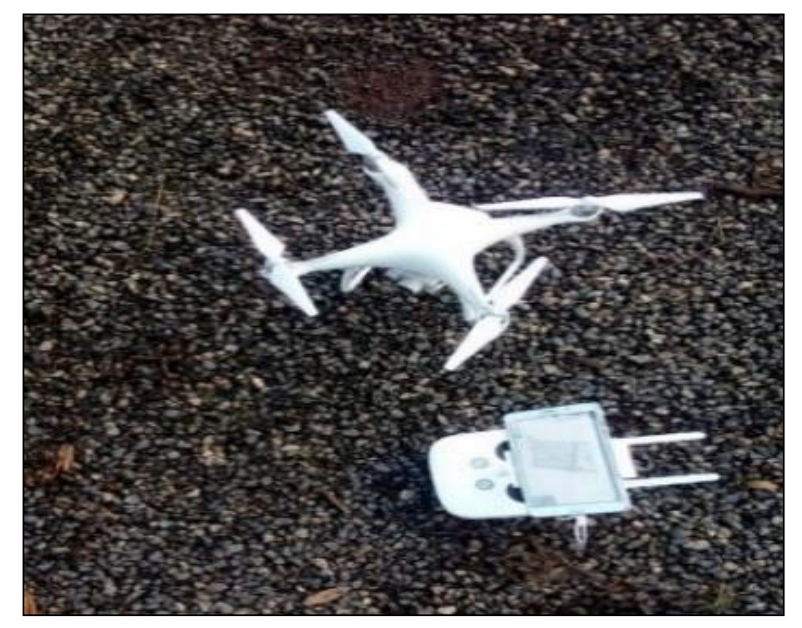

Fig. 1 DJI Phantom 4 UAV

Table 1 Specifications of Phantom 4 UAV

\begin{tabular}{|l|l|}
\hline Model & DJI Phantom 4 \\
\hline Camera & $\begin{array}{l}\text { Phantom } \\
\text { VisionFC 4000 }\end{array}$ \\
\hline Still camera resolution & 12 Mega pixels \\
\hline Max image size & $4000 \times 3000$ \\
\hline Operating range & 5000 \\
\hline Max video resolution & $4 \mathrm{~K}$ \\
\hline Smart rating & 100 \\
\hline Focal length (mm) & 3.6125 \\
\hline Flight time & 28 min \\
\hline Positioning system & $\begin{array}{l}\text { On-board } \\
\text { GPS/GLONASS }\end{array}$ \\
\hline
\end{tabular}

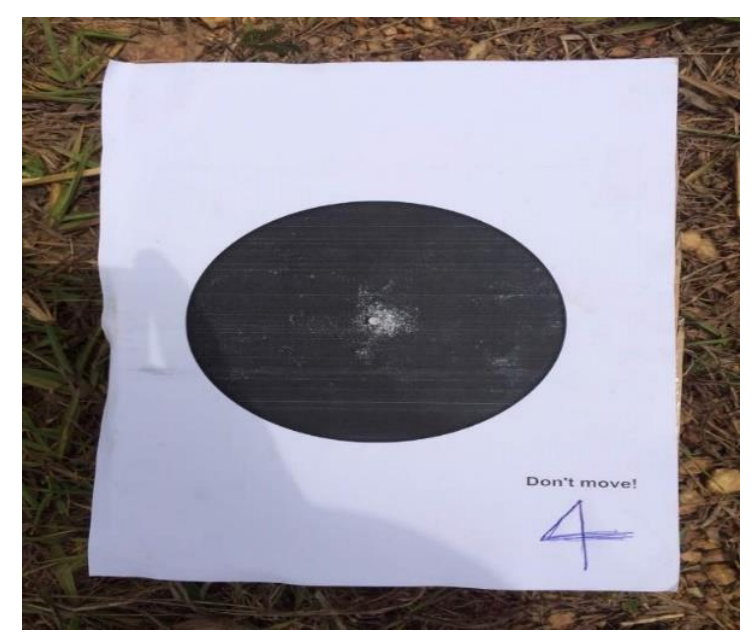

Fig. 2 Ground Control Point (Target)

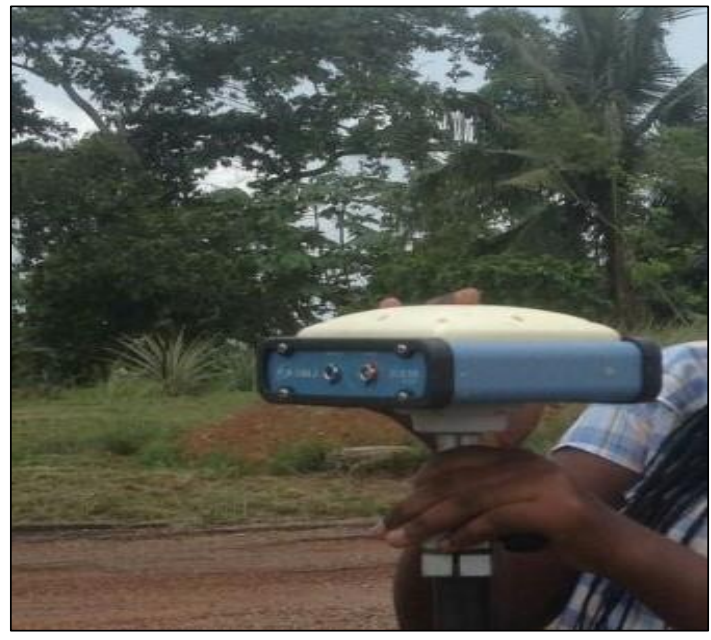

Fig. 3 South S86 GNSS Receiver

\subsection{Methods}

The method used in this study involves fieldwork and office work: The fieldwork consists of two sections. The UAV data acquisition and GNSS surveys. Fig. 4 shows the work flow for UAV and GNSS/GNSS procedure.

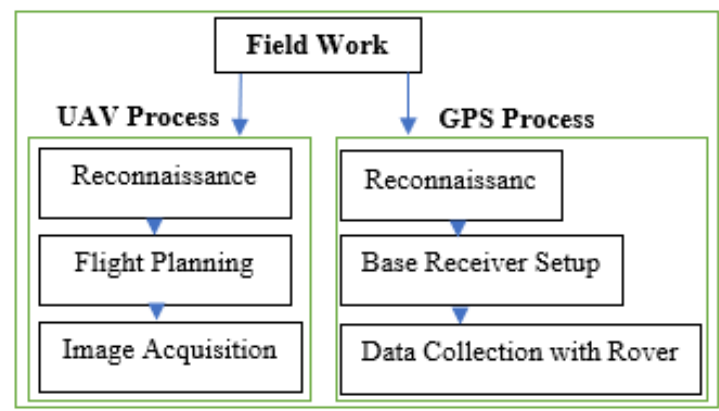

\section{Fig. 4 UAV and GNSS Survey Fieldwork Procedure}

Reconnaissance was carried out and suitable areas pre-marked immediately before flying, by placing the printed targets of appropriate shape and colour in a more or less even distribution across the mapping space or they can be naturally occurring features. Whether pre-marked or not, the printed targets were surveyed to determine their precise coordinates in a defined spatial reference (Table 2). The following inputs were required before flight; a polygon marking the outline of the area to be mapped and waypoints; flying height (altitude above ground level); camera geometry (focal length and sensor dimensions); longitudinal (forward) (\%) and lateral (side) overlap (\%). Flight plans can be edited either in the graphical or the tabular sections of the monitor. Using DroneDeploy software, the flight plan of the area was defined and the images were captured. The GNSS survey fieldwork also involved comprehensive planning and reconnaissance survey 
to primarily determine suitable existing control points in the study area. The selected control points should be accessible and visible from the skies. Furthermore, the area to be mapped must be determined. The GNSS Base receiver is set-up on a ground control point and the configuration checked. The Base receiver is also centered over the existing control points using a precise optical plummet. The height of the antenna is measured and recorded in a field book, together with the station name, the date and time, and other pertinent information. The GNSS Rover receiver is mounted to collect data of boundary points (Table 3 ) within specified time, applying all the necessary checks and configurations.

Table 2 Coordinates for Ground Control Points

\begin{tabular}{|c|c|c|}
\hline Point ID & Eastings (m) & Northings (m) \\
\hline GCP 1 & 609433.836 & 585529.464 \\
\hline GCP 2 & 609400.960 & 585539.047 \\
\hline GCP 3 & 609422.035 & 585587.920 \\
\hline
\end{tabular}

Table 3 Coordinates of Boundary Points from GNSS Surveys and Control Stations

\begin{tabular}{|l|c|c|}
\hline Point ID & $\begin{array}{c}\text { Eastings } \\
(\mathbf{m})\end{array}$ & $\begin{array}{c}\text { Northings } \\
(\mathbf{m})\end{array}$ \\
\hline SGW D904/13/24 & 610770.394 & 585868.636 \\
\hline BP 1 & 609461.300 & 585536.442 \\
\hline BP 2 & 609414.687 & 585551.483 \\
\hline BP 3 & 609468.098 & 585570.660 \\
\hline BP 4 & 609433.443 & 585584.723 \\
\hline SGW D904/13/25 & 610592.417 & 585747.415 \\
\hline
\end{tabular}

Office Work: The office work is done immediately after the field data acquisition. The office work for the GNSS surveys were as follows: The GNSS survey data of the boundary points were downloaded on a desktop computer and processed using appropriate software. This ensures that a back-up copy of all raw data is maintained for security reasons. All data collected and stored in the receiver relate to the World Geodetic System of 1984 (WGS84) reference ellipsoid. It is recommended that the data be processed in WGS 84 and converted to the local datum once processing is completed.

However, these transformations require some knowledge of the relationship between the two systems. The differential correction process may be conceptually divided into the following steps: specifying and preparing the base data file(s); entering the reference position of the base station; specifying and preparing the rover data file(s); differentially correcting the data, outputting the results; and transforming the results to local datum. The data collected and processed as described above are of little value to the property and land registration system unless they are presented in graphical format. This formatting represents the final step, and one of the most critical, in the proposed GNSS methodology, since it ensures that the data obtained from GNSS receiver are compatible with the traditional measurement process currently utilised for parcel mapping.

\subsubsection{Drone Data Processing}

The images captured were processed using Agisoft photoscan 1.2 pro software. Image Orientation was carried out. Image orientation (bundle block adjustment) consists of Interior orientation and Exterior Orientations (Jaramillo, 2000). Interior orientation (IO) involves the determination of the interior geometry of the camera (Camera is precalibrated) (Table 4).

Table 4 Camera Information

\begin{tabular}{|l|l|l|l|l|}
\hline $\begin{array}{l}\text { Camera } \\
\text { Model }\end{array}$ & Resolution & $\begin{array}{l}\text { Focal } \\
\text { Length }\end{array}$ & $\begin{array}{l}\text { Pixel } \\
\text { Size }\end{array}$ & $\begin{array}{l}\text { Pre- } \\
\text { calibrated }\end{array}$ \\
\hline $\begin{array}{l}\text { Phantom } \\
\text { VisionFC } \\
4000\end{array}$ & $4000^{\times}$ & 3.6125 & $\begin{array}{l}1.55 \\
\times 1.55\end{array}$ & Yes \\
$\mu \mathrm{m}$ & \\
\hline
\end{tabular}

The exterior orientation on the other hand comprises of both relative orientation (which includes Tie points extraction, matching and bundle adjustment) and absolute orientation (i.e. determining the position of images in the $3 \mathrm{D}$ ground coordinate.

\subsubsection{Orthophoto Quality Assessment}

The positional accuracies were determined by comparing the Northings and Eastings coordinates from the UAV and the GNSS (Table 5). Both coordinate components had errors in the same interval. The mean errors obtained were $0.053 \mathrm{~cm}$ and $0.041 \mathrm{~cm}$ (Table 5) with a standard deviation of 0.122 . The spatial distribution of errors from the orthophotos showed random behavior. These results are within acceptable accuracy requirements (Barry and Coakley, 2013).

Table 5 Discrepancies of GCPs as Measured with GNSS and UAV

\begin{tabular}{|c|c|c|}
\hline Points & Northings & Eastings \\
\hline BP1/DP1 & +0.211 & +0.191 \\
\hline BP2/DP2 & +0.007 & -0.082 \\
\hline BP3/DP3 & -0.076 & -0.037 \\
\hline BP4/DP4 & -0.089 & -0.041 \\
\hline Total Error & $\mathbf{+ 0 . 0 5 3}$ & $\mathbf{+ 0 . 0 3 1}$ \\
\hline
\end{tabular}




\section{Results and Discussion}

\subsection{Results}

The coordinates processed from both UAV and GNSS Surveys were used to produce cadastral plans of the study area. Cadastral plans for both UAV and GNSS were superimposed (Figs. 7 and
8). The green lines represent the boundary for UAV and the red lines represent the boundary for the GNSS. Fig. 5 and Fig. 6 show cadastral plans from UAV and GNSS respectively. Fig. 7 shows the overlay of cadastral plans from UAV and GNSS Surveys while Fig. 8 shows the overlay of GNSS and UAV Cadastral Plans on the orthophoto of the study area.

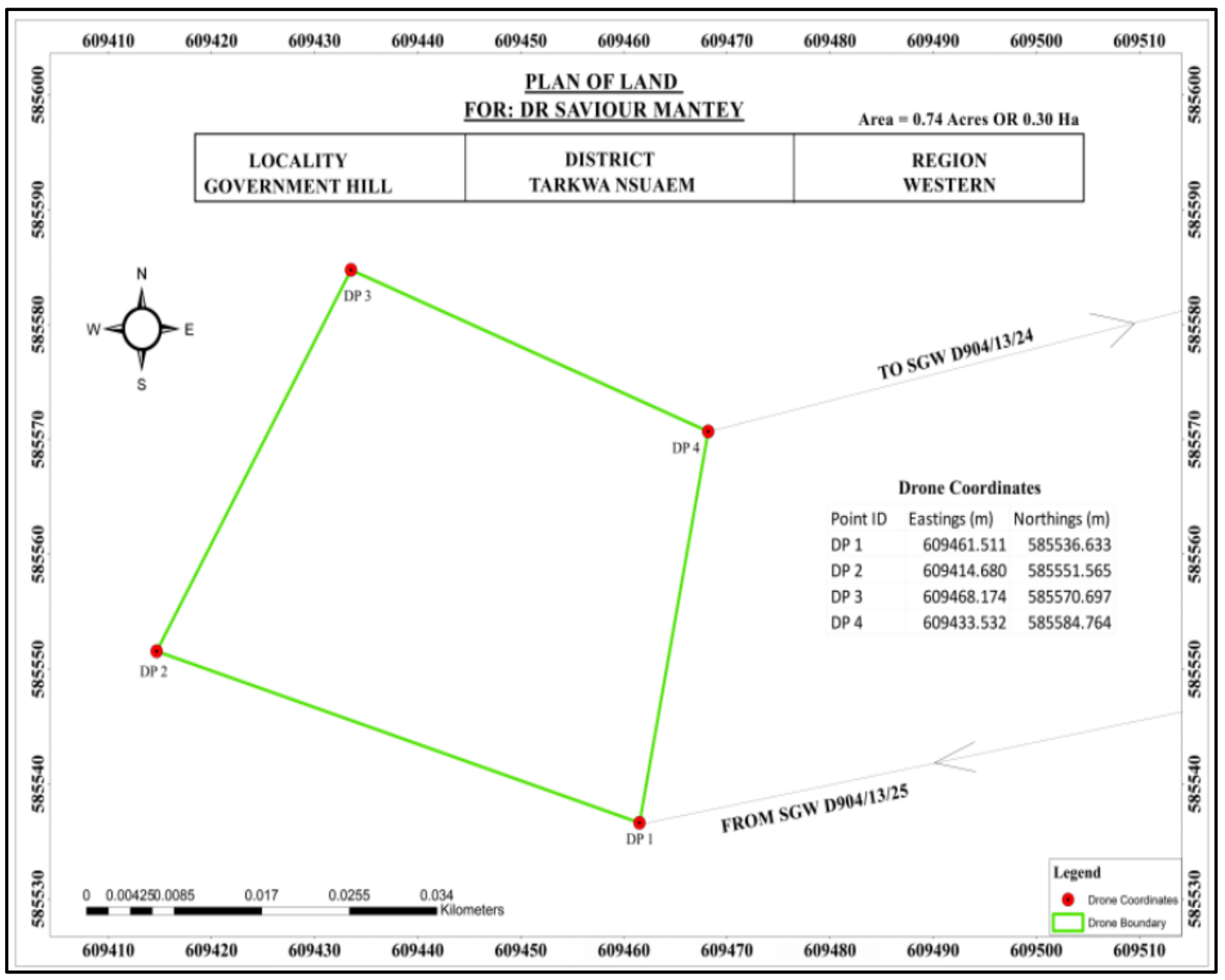

Fig. 5 Cadastral Plan from UAV Surveys 


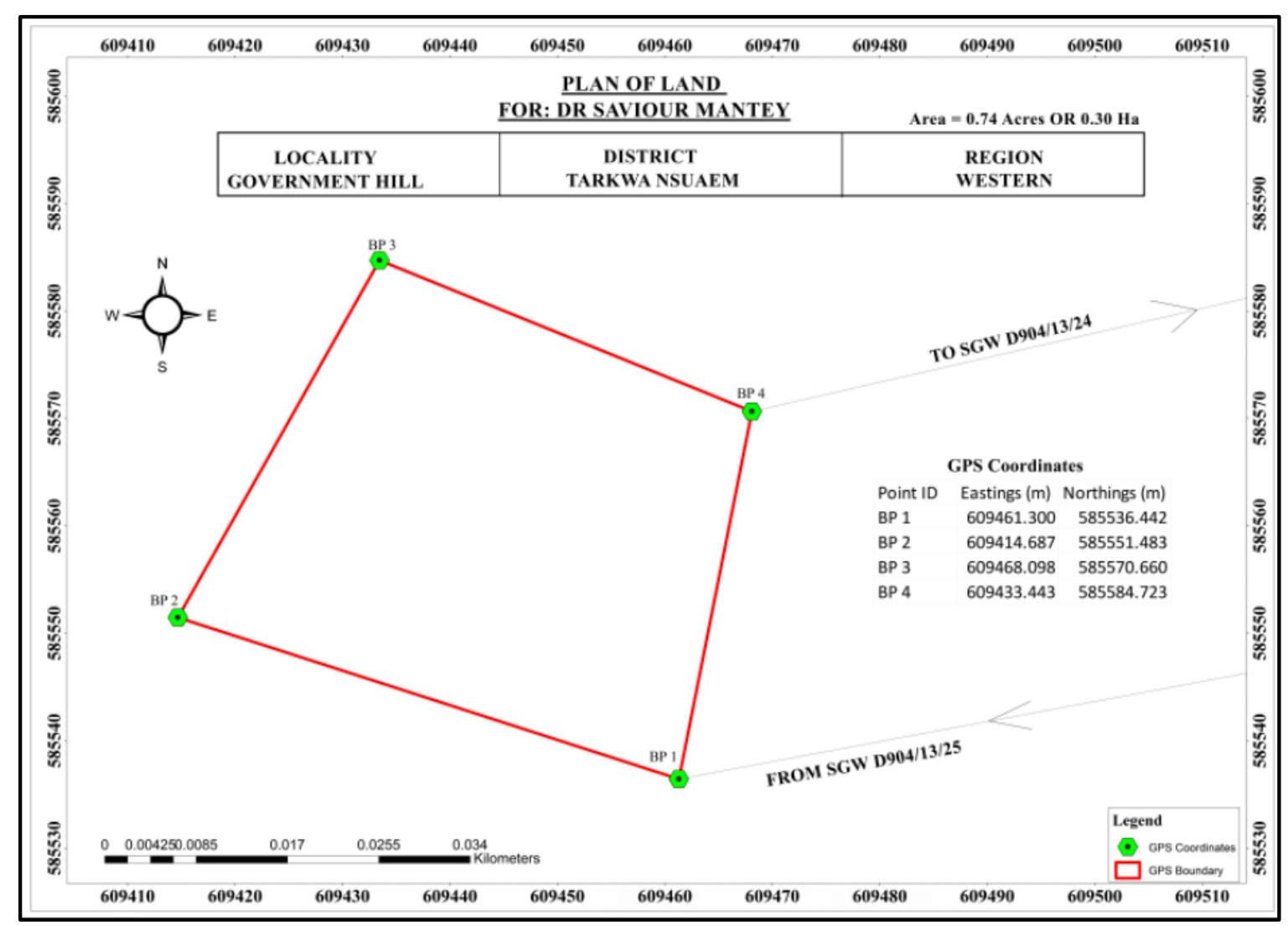

Fig. 6 Cadastral Plan from GNSS Surveys

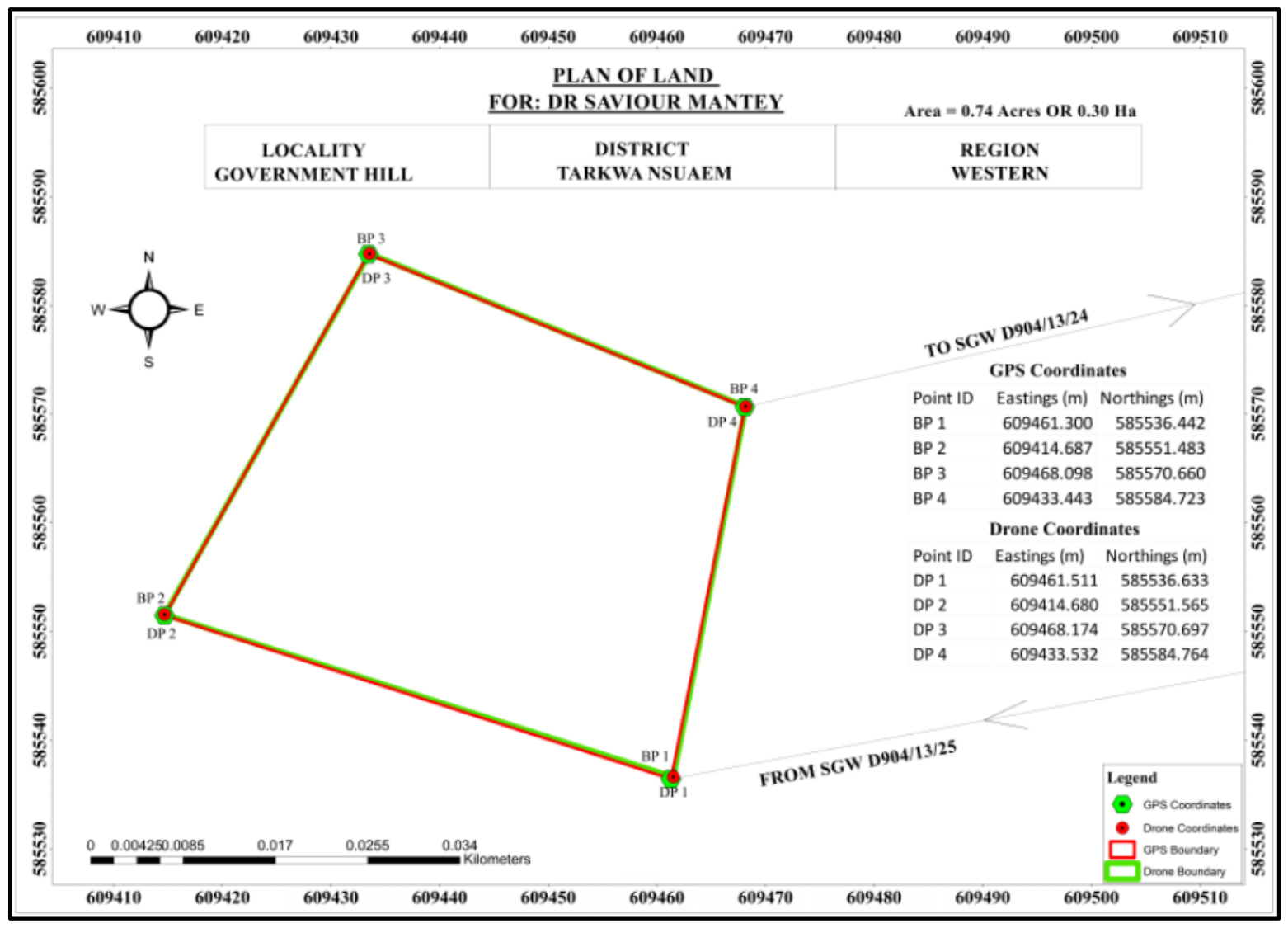

Fig. 7 Overlay of Cadastral Plan from UAV and GNSS Surveys 


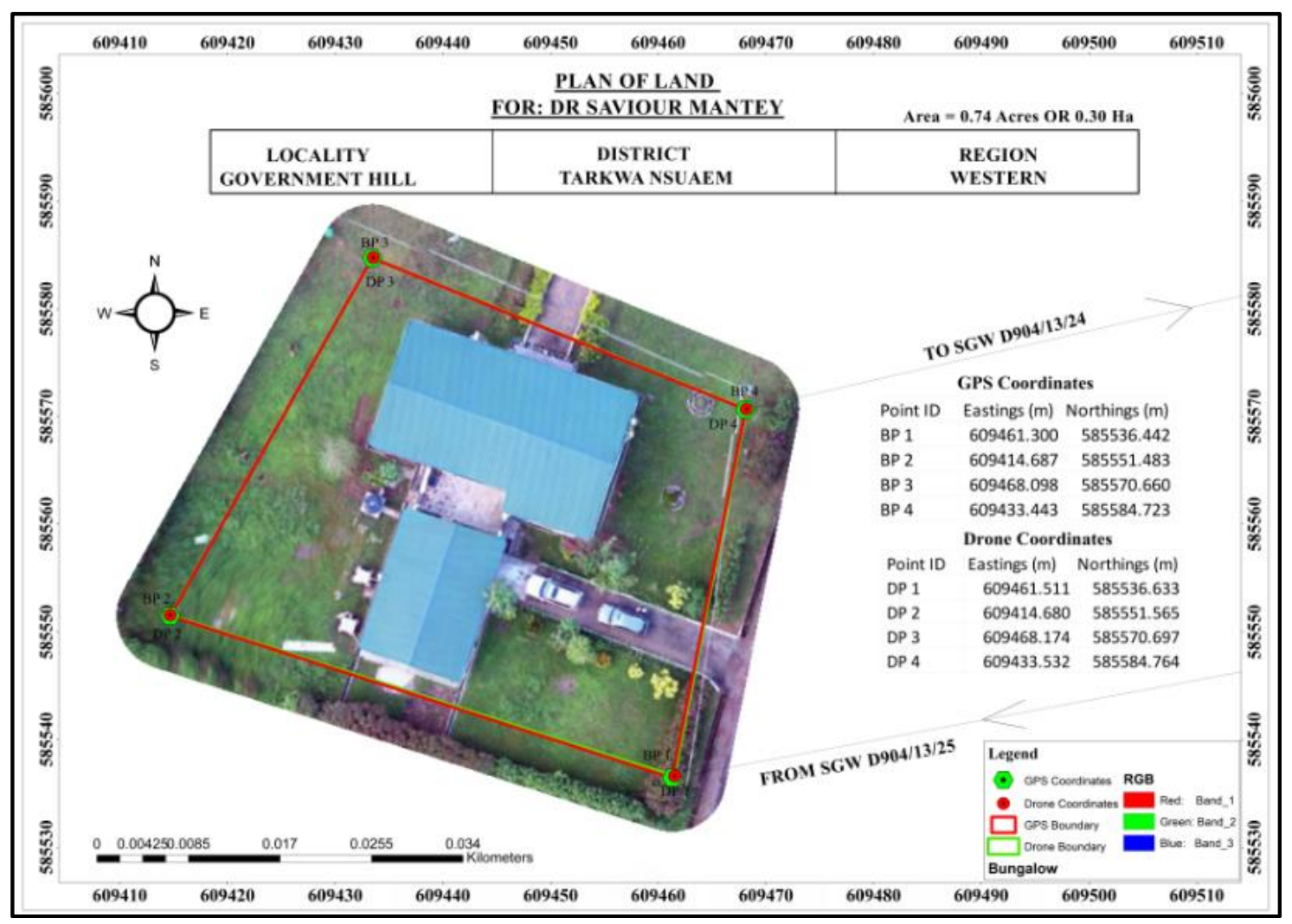

Fig. 8 Overlay of GNSS and UAV Cadastral Plans on Orthophoto of Study Area

\subsection{Discussion}

The cadastral plans produced for the UAV is assessed based on the differences between the coordinates for the boundaries and also the discrepancies of the GCP as measured in the photogrammetric software for the assessment of the quality of the orthophoto and also the deviation of the plan of the UAV from the cadastral plan produced from the GNSS. The cadastral surveying system gives preference to the survey records of parcel boundary positions over physical locations of landmarks on the ground. Cadastral plans provide information with the coordinates of the landmarks and site plans within a particular national geodetic coordinate reference system in a country. In case of lost or disputed boundary of a land parcel, it is this record or register that takes the precedence over marks on the ground.

\section{Conclusions and Recommendations}

\subsection{Conclusions}

Both UAV and GNSS Surveys were confirmed to be comparable in terms of accuracy and completeness. The difference in Northings and
Eastings from UAV and GNSS surveys which were $+0.380 \mathrm{~cm}$ and $+0.351 \mathrm{~cm}$ respectively were well within the tolerance of +/- $0.9114 \mathrm{~m}$ set by the Survey and Mapping Division (SMD) of the Lands Commission for cadastral plans production. This research therefore concludes that high resolution images from UAVs are suitable for cadastral surveying. The preference of UAV systems is the capability to quickly observe large areas at low flying altitude while still conforming to accuracy requirements of cadastral surveying. In areas where accessibility is difficult, UAVs offer a valuable alternative to GNSS Surveys.

\subsection{Recommendations}

For large areas where it is expensive and time consuming to apply Total Station or GNSS survey techniques, the UAV could be deployed to achieve the same results. Also, when safety of surveyors is at risk the use of UAV is suitable.

\section{References}

Anon., (2012), Ghana Statistical Service, 2010 Population and Housing Census, http://www.statsghana.gov.gh, Accessed: 23rd March, 2019.

Anon., (2017), "Unmanned Aerial Vehicle" https://www.techopedia.com/definition/29896/u nmanned-aerial-vehicle-uav, Accessed: March 
19, 2019.

Barry, P. and Coakley, R., (2013), “Accuracy of UAV Photogrammetry Compared with Network RTK GNSS" International Archives of Photogrammetry and Remote Sensing, Vol. XL1/W2, pp. 27-31.

Darwin, N., Hamid, N.F.A., Udin, W.S. and Mohd, N.A.B., (2013), "Light Weight Rotatory-Wing UAV for large scale mapping applications", Asia Geospatial Forum, Kuala Lumpur, Malaysia, pp. 24-26.

Eisenbeiss, H., (2011), "The Potential of Unmanned Aerial Vehicles for Mapping”, Fritsch/Spiller Edition, Photogrammetric Week, Wichmann Verlag, Heidelberg, pp. 135-145.

Everaerts, J., (2008), "The Use of Unmanned Aerial Vehicles ( UAVS ) for Remote Sensing and Mapping", The international Archives of the Photogrammetry, Remote Sensing and Spatial Information Sciences., vol. 37, pp. 1187-1192.

Ferruz, J., Manuel Vega, V. Ollero, A. and Blanco, V. (2011) "Reconfigurable Control Architecture for Distributed Systems in the HERO Autonomous Helicopter", Industrial Electronics IEEE Transactions, Vol. 58, No. 12, pp. 53115318.

Jaramillo J., (2000), "Mathematical Rectification of aerial photographs for cadastral mapping in Bolivia", International Archives of Photogrammetry and Remote Sensing, Vol. XXXIII, Part B4. Amsterdam, pp. 394-399.

Kavannagh, B. F. and Glenn Bird, S. J., (2000), Surveying: Principles and Applications, $5^{\text {th }}$ Edition, Prentice Hall, Incorporated, Pearson Education, Upper Saddle River, New Jersey pp. 546-599.

Lee, K. S., Ovinis, M., Nagarajan, T., Seulin, R. and Morel, O. (2015), "Autonomous patrol and surveillance system using unmanned aerial vehicles", Environment and Electrical Engineering (EEEIC) 2015 IEEE 15th International Conference on, pp. 1291-1297.

Lippiello, V. and Siciliano, B. (2012), "Wall inspection control of a VTOL unmanned aerial vehicle based on a stereo optical flow", Intelligent Robots and Systems (IROS) 2012 IEEE/RSJ International Conference, pp. 4296-4302.

Manyoky, M. Theiler P., Steudler D., Eisenbeiss H. (2011), "Unmanned aerial vehicle in cadastral applications", International Archives of the Photogrammetry, Remote Sensing and Spatial Information Sciences, Vol. XXXVIII-1/C22, pp. 57-62.

Merz, T. and Chapman, S. (2011), "Autonomous Unmanned Helicopter System For Remote Sensing Missions In Unknown Environments", The International Archives of the Photogrammetry, Remote Sensing and Spatial
Information Sciences, XXXVIII-1/C22, pp.143148.

Saripalli, S., Montgomery, J. F., and Sukhatme, G. S. (2003), "Visually-guided landing of an unmanned aerial vehicle", IEEE Transactions on Robotics and Automation, Vol. 19 No. 3, pp. 371-381.

Valavanis, K.P. (2008), “Advances in Unmanned Aerial Vehicles: State of the Art and the Road to Autonomy", Springer Science \& Business Media, Vol. 33, 543pp.

Williamson, I. P. (1997), "The Justifiation of Cadastral Systems for Developing Countries", Geomatica, Vol.51 No. 1, pp. 21-36.

Witayangkurn, A., Nagai, M., Honda, K., Dailey, M., and Shibasaki, R. (2011), "Real-Time Monitoring System Using Unmanned Aerial Vehicle Integrated With Sensor Observation Service", The International Archives of the Photogrammetry, Remote Sensing and Spatial Information Sciences, Vol. XXXVIII-1/C22, pp.107-112.

\section{Authors}

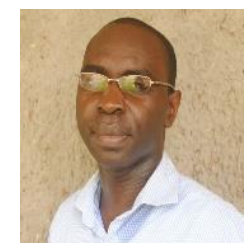

Saviour Mantey is a Senior Lecturer at the Department of Geomatic Engineering of the University of Mines and Technology (UMaT), Tarkwa, Ghana. He holds a Bachelor of Science degree in Geomatic Engineering from the Kwame Nkrumah University of Science and Technology, Kumasi, Ghana. He obtained his Master of Philosophy degree and Doctor of Philosophy from University of Cambridge and University of Mines and Technology respectively. His research interest includes application of Remote Sensing and GIS in Health and Environmental Analysis, UAVs and Web GIS applications.

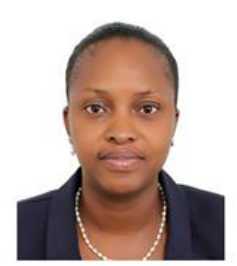

Naa Dedei Tagoe is a Senior Lecturer at UMaT-Ghana. She was awarded BSc. degree in Geodetic Engineering at KNUST-Ghana. She obtained her MSc. degree in Photogrammetry and Geoinformatics from Stuttgart University of Applied Sciences, Germany. She also holds $\mathrm{PhD}$ in Geomatics from University of Cape Town. Her research interests include Close Range Photogrammetry, 3D Modelling of Cultural Heritage Sites, Remote Sensing, UAVs and Web-GIS Applications. She is a Member of IFUW. 